\title{
Male circumcision and HIV prevention: Directions for future
} research

Johannes van Dam

Marie Christine Anastasi

Follow this and additional works at: https://knowledgecommons.popcouncil.org/departments_sbsr-hiv

Part of the International Public Health Commons, and the Public Health Education and Promotion Commons How does access to this work benefit you? Let us know!

\section{Recommended Citation}

van Dam, Johannes and Marie Christine Anastasi. 2000. "Male circumcision and HIV prevention: Directions for future research," Horizons Report. Washington, DC: Population Council. 
Horizons

Male Circumcision and HIV Prevention Directions for Future Research

Johannes van Dam, M.D., MPH Marie-Christine Anastasi, M.A. 
USAID This publication was made possible through support provided by the Office of Health and Nutrition, Global Bureau, U.S. Agency for International Development, under the terms of HRN-A-00-9700012-00. The opinions expressed herein are those of the authors and do not necessarily reflect the views of the U.S. Agency for International Development.

Published in June 2000.

\section{Population Council}

The Population Council is an international, nonprofit, nongovernmental institution that seeks to improve the wellbeing and reproductive health of current and future generations around the world and to help achieve a humane, equitable, and sustainable balance between people and resources. The Council conducts biomedical, social science, and public health research and helps build research capacities in developing countries. Established in 1952, the Council is governed by an international board of trustees. Its New York headquarters supports a global network of regional and country offices.

\section{Table of Contents}

Executive Summary 1

$\begin{array}{ll}\text { Introduction } & 3\end{array}$

Research Findings and Gaps 5

Evidence for a Protective Effect of Male Circumcision 5

Biology or Behavior: The Role of Foreskin, Hygiene, and Risk Behavior 6

\section{Discussion of Operations Research Issues}

Traditional and clinical circumcision practices - are they safe? 9

$\begin{array}{ll}\text { Acceptability of male circumcision as a public health intervention } & 10\end{array}$

$\begin{array}{ll}\text { Age at circumcision } & 12\end{array}$

$\begin{array}{ll}\text { Gender and ethical issues } & 13\end{array}$

Is male circumcision a feasible public health intervention? 15

$\begin{array}{ll}\text { Behavioral implications of male circumcision } & 16\end{array}$

The effect of male circumcision on male-to-female transmission of HIV $\quad 17$

$\begin{array}{ll}\text { Cost-effectiveness of male circumcision in HIV prevention } & 17\end{array}$

$\begin{array}{ll}\text { Conclusions and Recommendations } & 19\end{array}$

Recommendations for Public Health Research 20

$\begin{array}{ll}\text { Recommendations for the Horizons Project } & 21\end{array}$

$\begin{array}{ll}\text { References } & 22\end{array}$

Appendix A: List of Participants 23

Appendix B: Meeting Agenda 26 


\section{Executive Summary}

growing body of scientific publications suggests that
male circumcision is associated with a reduced risk of
HIV infection in sub-Saharan Africa. Thus, male circumcision is being considered as a potential intervention in the prevention of sexually transmitted HIV infection, even though this procedure has profound cultural implications and carries the risk of complications, and its benefits are realized only many years later.

This report presents the findings of a meeting of international researchers, organized by the Horizons Project, to explore the programmatic and research implications of the association between male circumcision and HIV prevention. Most studies on male circumcision and HIV infection have been done in Africa, and the discussion focused largely on this continent. The conclusions and recommendations from the meeting, however, may be relevant for other parts of the world where the HIV epidemic continues to expand and where heterosexual transmission is a major issue.

Based on the discussion during the two-day meeting, participants determined that there is considerable evidence supporting a protective effect of male circumcision on HIV infection in men in sub-Saharan Africa. Participants also concluded that there are "The promotion or institution of a
procedure that has profound cultural
implications, risks of complications, and
benefits that are realized only decades
later represents a formidable public
health and political challenge."
-Myron S. Cohen, University of
North Carolina many unknowns. These relate to the mechanisms and the role of the foreskin in the acquisition of HIV infection by men; the existence of, as yet, unexplored confounders in the attribution of causality; and the expected effect of male circumcision on HIV infection in different populations. Little is known about the impact and cost-effectiveness of male circumcision among high-risk versus lower-risk seronegative men, while questions remain about the relationship between age of circumcision and risk of HIV infection. There is very little experience concerning the practicality, feasibility, acceptability, and cost-effectiveness of male circumcision as an HIV intervention. The effect of male circumcision on male and female risk behavior and condom use is not known, but behavioral changes related to circumcision status that result 


\section{Horizons}

in reduced protection and increased risk-taking could well reduce the beneficial effect of male circumcision.

To answer many of these concerns, randomized controlled trials (RCTs) should ideally be conducted to allow for the study of these and a number of other variables related to HIV transmission. Such RCTs are probably most feasible among potentially high-risk males, but they are nevertheless fraught with methodological and ethical difficulties. Studies on attitudes toward and understanding of the benefits of male circumcision are relatively easy to conduct, as is an assessment of current circumcision practices. The operational aspects of introducing a male circumcision program and of maintaining quality and guaranteeing safety should also be explored.

Thus, while it may be premature to recommend male circumcision in currently non-circumcising communities, research on male circumcision should be done in populations where circumcision is currently practiced, and acceptability studies can be done elsewhere. A rapid assessment tool that examines the feasibility and cost of male circumcision interventions should be developed and operations research conducted in preparation for possible male circumcision programs.

Recommendations for the Horizons Project in particular include integration of assessment of attitudes toward and acceptability of male circumcision in ongoing studies, development and field test of a rapid assessment tool, collaboration in modeling the cost and impact of male circumcision interventions, and development of proposals for longer-term studies on cost, safety, and outcomes of male circumcision in the context of HIV prevention. 


\section{Horizons}

Introduction

Statement of the Problem

s we enter a third decade of living with HIV/AIDS, there
is still no cure-and no vaccine to protect against the
virus that has infected more than 33 million people since it was first recognized in the early 1980s. Most industrialized countries have seen a decline in AIDS-related mortality over the past few years, largely due to antiretroviral drugs, but rates of HIV infection and of AIDS-related mortality continue to soar in most of Africa and Asia and in parts of Latin America, Eastern Europe, and Central Asia. ${ }^{1}$ As

' AIDS epidemic update: December national HIV prevention programs are being implemented, 1999. Geneva: UNAIDS and WHO. research continues to better understand the determinants of the HIV epidemic and the differences in HIV prevalence between populations within countries and between countries or regions.

A significant number of descriptive and ecological studies have pointed to a relationship between male circumcision and HIV infection in males. Male circumcision-the surgical removal of all or part of the prepuce (foreskin) of the penis-may be practiced as part of a religious ritual performed shortly after birth, a

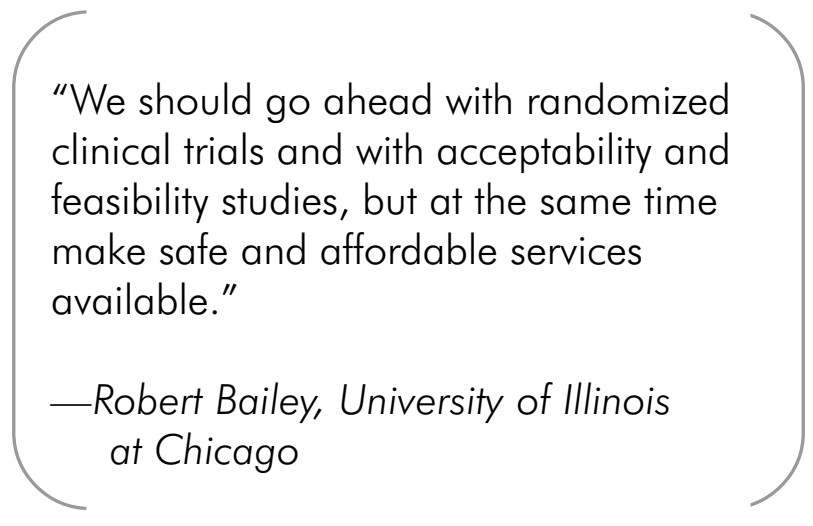
traditional "coming of age" ritual practiced at or after puberty in certain cultures, or a medical procedure related to infections, injury, or anomalies of the foreskin. It is increasingly being considered as a preventive medical procedure to reduce the acquisition of sexually transmitted HIV infection.

A meta-analysis conducted by Hayes and colleagues "provides conclusive evidence that male circumcision is associated with a reduced risk of HIV infection in sub-Saharan Africa... |thus| it is time to consider the acceptability and feasibility of introducing male circumcision as part of the HIV prevention strategy in areas of Africa where men do not traditionally circumcise". ${ }^{2}$ However, as Cohen points out, "the promotion or institution of a procedure that has pro-

\footnotetext{
2 Hayes R, H Weiss and M Quigley. 1999. Meta-analysis on the relationships between male circumcision and HIV infection. Presented at the $13^{\text {th }}$ meeting of the ISSTDR, Denver, Colorado, USA, 11-14 July.
} 


\section{Horizons}

found cultural implications, risk of complications, and benefits that are realized only decades later represents a formidable public health and political challenge". ${ }^{3}$

To explore the programmatic and research implications of the association between male circumcision and HIV prevention, the Horizons Project convened a two-day meeting of leading international researchers in Washington, D.C., on February 7-8, 2000. The meeting addressed the following key questions:

${ }^{*}$ Is there sufficient evidence to propose male circumcision as a feasible public health intervention to slow the spread of HIV?

*What are the operations research issues relevant to male circumcision and HIV prevention?

* What are the next steps to be taken in the area of male circumcision and HIV research?

The literature indicates that most studies on male circumcision and HIV infection have been conducted in sub-Saharan Africa. The discussions at the Horizons meeting focused largely on the African continent (where two-thirds of people infected with HIV live), although the conclusions and research recommendations may be relevant for other parts of the world where the HIV epidemic continues to expand and where heterosexual transmission is a major issue.

This report presents the findings of the meeting in three parts. It begins with a discussion of the current state of research and an identification of major gaps in our knowledge or understanding. This is followed by a discussion of operations research issues. The report concludes by listing recommendations for future research, including more general recommendations and those specific to Horizons' mandate of applying an operations research approach to identifying and disseminating best practices with regard to preventing HIV and reducing the impact of HIV/AIDS.

\footnotetext{
${ }^{3}$ Cohen MS. 2000. Preventing Sexual Transmission of HIV - New Ideas from Sub-Saharan Africa. New Engl J Medicine 342 (13): 970-2.
} 


\section{Research Findings and Gaps}

\section{Evidence for a Protective Effect of Male Circumcision}

$\mathrm{T}$ here is considerable relational evidence in the literature suggesting a protective effect of male circumcision on HIV acquisition by men. A decade ago, in a study of geographic patterns of male circumcision practices in Africa, investigators found significant differences in HIV seroprevalence in populations that practice male circumcision compared to populations that do not. ${ }^{4}$ More recently this relationship was confirmed in a large, community-based, multi-site study comparing risk factors for HIV infection in two cities with low HIV prevalence with those found in two cities with a high prevalence of HIV infection. ${ }^{5}$ A meta-analysis of studies examining the relationship between male circumcision and the risk for HIV infection among males in sub-Saharan Africa concluded that uncircumcised men are twice as likely as circumcised men to be HIV infected (adjusted relative risk $=0.42,95 \%$ CI 0.34-0.54). The effect was stronger among men at high risk for HIV (adjusted $R R=0.29,95 \% \mathrm{CI} 0.20-0.41$ ) than among men in the general population (adjusted $\mathrm{RR}=0.56,95 \% \mathrm{CI}$ 0.44-0.70). The authors considered this effect strong enough that it is unlikely to be explained by residual confounding factors. ${ }^{6}$

Halperin and Bailey ${ }^{7}$ estimate that in countries such as Nigeria and Indonesia, where about 20 percent of men are not circumcised, the lack of circumcision may account for approximately 23 percent of all heterosexual HIV-1 infections. However, in countries like Zambia and Thailand, where 80 percent of men are not circumcised, lack of circumcision may account for as much as 55 percent of HIV- 1 infections. ${ }^{8}$ It should be noted, though, that in large parts of the African continent, male circumcision is done for religious reasons on Muslim children. Muslims may well, in general, have a lower risk profile than non-Muslims, and thus be at lower risk for acquiring HIV infection. The confounding effect of religion has been inadequately studied.
${ }^{4}$ Moses S, JE Bradley, NJD Nagelkerke et al. 1990. Geographical Patterns of Male Circumcision Practices in Africa:

Association with HIV Seroprevalence. Int J Epidemiology 19 (3): 693-7

${ }^{5}$ Buve A, for the Study Group on Heterogeneity of HIV Epidemics in African Cities. 2000. HIV/AIDS in Africa: Why So Severe, Why So Heterogeneous? Presented at the $7^{\text {th }}$ Conference on Retroviruses and Opportunistic Infections, Abstract S28, San Francisco, CA, USA, Jan 30 - Feb 2 .

${ }^{6}$ Hayes R, H Weiss and M Quigley. 1999. Meta-analysis on the relationships between male circumcision and HIV infection. Presented at the $13^{\text {th }}$ meeting of the ISSTDR, Denver, Colorado, USA, 11 14 July.

${ }^{7}$ Halperin D \& RC Bailey. 1999. Male
circumcision and HIV infection: 10 years
and counting. Lancet 354 (192): 1813-5

${ }^{8} \mathrm{lbid}$. 


\section{Horizons}

\section{Biology or Behavior: The Role of the Foreskin, Hygiene, and Risk Behavior}

Little is known about the biological mechanism by which males are infected with sexually transmitted HIV or about the role of the foreskin in relation to such infection. The foreskin has a high density of Langerhans cells, which represent a possible source of initial cell contact for HIV infection. ${ }^{9}$ In addition the foreskin may provide an environment for survival of bacterial and viral matter and may be susceptible to tears, scratches, and abrasions, which suggests that its presence may increase the likelihood of contracting HIV. ${ }^{10}$

The amount of foreskin left after circumcision is highly variable, ranging from a complete removal to the foreskin being largely still present. Pépin and colleagues found HIV-2 infection to be more common among men who are functionally uncircumcised, despite having undergone ritual circumcision ( $11 \%$ versus $5 \%, \mathrm{P}=0.17) .{ }^{11}$ None of the studies reported in the meta-analysis by Hayes and colleagues attempted to distinguish between complete and partial removal of the foreskin, and it was therefore not possible to assess the effect of such partial circumcisions. There is little information about the role of penile hygiene in protecting against HIV infection or other sexually transmitted infections, with most reported experience dating back to the preantibiotic era, when soap and water were used to reduce the prevalence of chancroid. ${ }^{12}$ No studies of male circumcision in Africa have attempted detailed study of sexual or hygienic practices. Among certain tribes in Kenya, however, personal hygiene was frequently quoted as a reason for circumcision, with both men and women perceiving circumcised men as cleaner and therefore more desirable sexual partners. ${ }^{13}$

Meeting participants identified the following gaps:

* The literature indicates that no studies to date have examined the effect of penile hygiene and especially postcoital cleansing on HIV transmission.

* The effect of the age at which circumcision takes place has not been adequately studied.

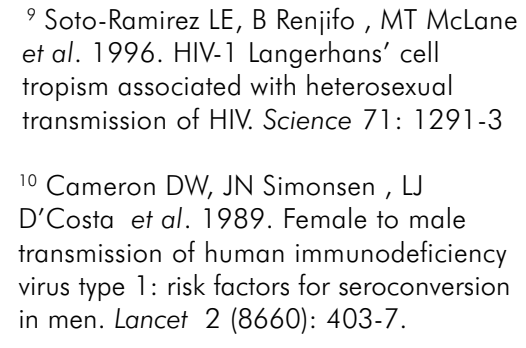

9 Soto-Ramirez LE, B Renjifo, MT McLane et al. 1996. HIV-1 Langerhans' cell tropism associated with heterosexual transmission of HIV. Science 71: 1291-3

${ }^{10}$ Cameron DW, JN Simonsen, LJ D'Costa et al. 1989. Female to male transmission of human immunodeficiency virus type 1: risk factors for seroconversion in men. Lancet 2 (8660): 403-7.

11 Pépin J, M Quigley, J Todd et al.
1992. Association between HIV-2
infection and genital ulcer diseases
among male sexually transmitted disease
patients in The Gambia. AIDS 6: 89-93.

${ }^{12}$ O'Farrell N. 1993. Soap and water prophylaxis for limiting genital ulcer disease and HIV- 1 infection in men in sub-Saharan Africa. Genitourin Med 69: 297-300.

\footnotetext{
${ }^{13}$ Bailey RC. 2000. personal communication.
} 
* There may be other confounders, such as the effect of religion, which need further study.

* The effect of male circumcision in core group members versus the general population has not been studied.

* While randomized clinical trials (RCTs) in different population groups are important to provide "gold-standard" evidence of the protective effect of male circumcision and for the promotion of research findings, no such studies have been done.

* The effect of partial versus more complete removal of the foreskin should be studied.

\section{Recommendations}

Ideally, RCTs should be done to study the effect on HIV transmission of male circumcision in high-risk groups as well as in the general population. Such studies should include a "penile hygiene" or "preand post-coital cleansing" arm. It was noted that, while RCTs would provide high standards of evidence for a protective effect of male circumcision on HIV transmission under different epidemiological situations, such studies would be fraught with ethical problems, methodologically difficult, time-consuming, and costly. It is possible that such studies could be conducted among men at increased risk of HIV infection, for whom the protective effect may be greater and studies may be more feasible.

Future observational studies should not rely on self-reporting but rather include a clinical examination of circumcision status to determine whether circumcision was total or partial, as well as recording the age at circumcision. 
Horizons 


\section{Discussion of Operations Research Issues}

W

hile there is relational evidence for a protective effect of male circumcision on HIV acquisition by men, there is little evidence for the acceptability, feasibility, and cost-effectiveness of male circumcision as a public health intervention. These issues need to be explored and better understood if appropriate decisions about the allocation of scarce intervention resources are to be made.

Meeting participants addressed the following:

* The safety of current traditional and clinical male circumcision practices in developing countries.

* The acceptability of male circumcision.

* Age at circumcision.

* Gender and ethical issues relating to male circumcision.

* The feasibility and cost of introducing male circumcision as a public health intervention.

* Behavioral consequences of introducing male circumcision.

* The effect of male circumcision on "Male circumcision is associated with a
significantly reduced risk of HIV infection
among men in sub-Saharan Africa,
particularly among men at high risk
for HIV."
-Helen Weiss, London School of
Hygiene and Tropical Medicine male-to-female transmission.

* The cost-effectiveness of male circumcision.

* The immediate next steps for operations research in this area.

Traditional and Clinical Male Circumcision Practices: Are They Safe?

Practices differ greatly in areas where male circumcision is routinely performed.

Circumcisions may be done in clinical settings by trained health professionals, or by religious or traditional practitioners whose methods and experience vary. There is anecdotal evidence that more and more traditional healers in some 


\section{Horizons}

sub-Saharan African countries are recommending male circumcision as a means of preventing HIV infection. Many of these healers lack training and may place boys and men at risk for complications such as infection or sepsis, hemorrhage, partial penile amputations, or even death. Some circumcision practices, such as using the same knife for each man during a circumcision ceremony, may increase the risk of transmitting HIV through blood-to-blood contamination. ${ }^{14}$ Cultural customs that surround circumcision, such as alcohol consumption and increased sexual activity, may be associated with increased risk of sexual transmission of STIs and HIV infection in some areas. ${ }^{15}$

\footnotetext{
${ }^{14}$ Bailey RC. 1999. UNAIDS Technical Update: Male Circumcision and HIV Prevention. First Draft. UNAIDS, Geneva.

${ }^{15}$ Bailey RC, S Neema, and R Othieno. 1999. Sexual Behaviors and Other HIV Risk Factors in Circumcised and Uncircumcised Men in Uganda. J Acquired Immune Defic Syndr 22: 294-301.
}

\section{Recommendations}

* Assess current practices in traditional as well as clinical settings. Consider the actual circumcision (techniques, instruments used, and sterilization) and the healing period.

* Assess the prevalence of risk-taking behavior associated with circumcision ceremonies and rituals.

* Assess the understanding of people undergoing circumcision and, in the case of children, their parents about the safety of male circumcision.

* Conduct intervention studies with health workers, traditional healers, and religious practitioners to implement safer male circumcisions, including use of sterile equipment.

\section{Acceptability of Male Circumcision as a Public Health Intervention}

To be an effective intervention, circumcision must be acceptable to local health ministries, religious and political leaders, health care personnel, and residents of the community.

There is some evidence that in parts of eastern and southern Africa, where male circumcision is already practiced to a certain extent, preference for circumcision may be increasing. ${ }^{16}$ A study among a convenience sample of 216 clinic

\footnotetext{
16 Halperin D and RC Bailey. 1999. Male circumcision and HIV infection: 10 years and counting. Lancet 354 (192): 1813-5.
} 
attendees in western Kenya indicated that 60 percent of men surveyed would prefer to be circumcised, while 62 percent of women would prefer their partner to be circumcised. ${ }^{17}$

Important determinants of the acceptability of male circumcision are:

* Social, cultural and religious beliefs with regard to male circumcision.

* Perceived health or social benefits of the procedure.

* Safety of the procedure and the rate of complications.

* Perceived pain and discomfort associated with male circumcision.

* Cost.

These factors are especially relevant where male circumcision is introduced as a public health intervention in a previously non-circumcising population.

To avoid potential stigmatization of those who choose to be circumcised in otherwise non-circumcising communities, it is important that a certain degree of community acceptability be achieved. On the other hand, there is anecdotal evidence for a considerable amount of peer pressure in some circumcising communities in Uganda for men to be circumcised. A number of men will avoid ceremonial circumcision by having the procedure done in health facilities. It might be possible to build on this in efforts to introduce male circumcision as a public health intervention. ${ }^{18}$

The acceptability of male circumcision to health care providers will influence the degree to which male circumcision is discussed as a possible way to prevent HIV infection, and affect willingness to perform the procedure.

A paradox may well be that male circumcision is most acceptable in areas where it is already practiced (and thus where the effect of a male circumcision program will be limited), while the intervention may be much less acceptable in currently non-circumcising communities. It is in the latter where the greatest effect on HIV incidence can be expected.
17 Bailey RC. 2000. personal communication.

${ }^{18}$ Kalibala S. 2000. personal communication. 


\section{Horizons}

1

\section{Recommendations}

* Assess the attitudes toward and acceptability of male circumcision in currently non-circumcising populations.

* Assess the understanding of the benefits and the social implications of male circumcision in circumcising and non-circumcising populations.

* Assess the acceptability of male circumcision to health care workers, both in traditionally circumcising and in non-circumcising communities.

\section{Age at Circumcision}

There is a wide degree of variation in the age at which circumcision is performed. In Kenya, the median age is 18 years (range 12 to 22 years), and it appears to be slowly rising. ${ }^{19}$ While it is likely that circumcision offers the same level of protection to HIV-negative men, regardless of the age at which it is performed, older men are more likely to be infected with HIV than younger men. In terms of a protective effect on HIV acquisition, it is likely that to be most effective, circumcision would have to be done before or soon after the onset of sexual activity. Kelly and colleagues found that men who were circumcised before puberty had a much reduced risk of prevalent HIV infection compared to men who were uncircumcised and that reduced risk of HIV is found largely among men circumcised between the ages of 13-20 years $(\mathrm{RR}=0.46,95 \% \mathrm{Cl}$ 0.28-0.77). In this study, circumcision after the age of 20 was found to be not significantly protective against HIV infection ( $R R=0.78,95 \% \mathrm{CI} 0.43-1.43) .{ }^{20}$

The potential for a reduced effect on HIV transmission of circumcision at an older age raises both an ethical and a practical issue: In view of resource limitations, should health care services in sub-Saharan Africa promote or offer circumcision preferentially to men under a certain age, such as 20 or 25 years? Should counseling and HIV testing precede circumcision at older ages?

19 Bailey RC. 2000. personal communi-
cation.

${ }^{20}$ Kelly R, N Kiwanuka, MJ Wawer et al. 1999. Age of male circumcision and risk of prevalent HIV infection in rural Uganda. AIDS 13: 399-405. 


\section{Recommendations}

* Model the effect of HIV incidence of male circumcision performed at different ages.

* Assess the age preference for male circumcision in circumcising and non-circumcising communities.

\section{Gender and Ethical Issues}

There are a number of gender-related implications to promoting and providing male circumcision services. While male circumcision may offer a direct and immediate benefit to seronegative men, particularly those at high risk of HIV infection, its usefulness as a HIV prevention strategy for women is less clear, since only one study has assessed the risk of transmission to HIV-negative women associated with the circumcision status of their HIV-positive male partner. There are some intriguing findings that circumcised males with low viral loads $(<50,000 \mathrm{c} / \mathrm{ml})$ may be less likely to transmit HIV infection to their female partners than uncircumcised men with low viral loads. ${ }^{21}$

${ }^{21}$ Gray, Ron. 2000. personal communication.

Advocating male circumcision in communities where female genital cutting (FGC) exists could have negative repercussions on efforts to eliminate FGC. Therefore, it was recommended that local women's health advocates working to abolish FGC be consulted about proposed male circumcision interventions to minimize conflicting messages about genital cutting. In addition, circumcision is often done as part of a puberty rite, and it may offer a unique opportunity to introduce more gender-equitable concepts of masculinity and sexuality as part of the socialization ceremony.

The recommended age of male circumcision has consequences for the process of obtaining informed consent for the procedure. Depending on age and maturity, a young boy may not fully understand the process of male circumcision and thus be unable to give informed consent. In such cases it is usual for parents to give their consent, but there is little 


\section{Horizons}

experience to indicate at which age the person undergoing the procedure should give consent. Some children's rights advocates feel that parental consent for circumcision, especially in infancy or childhood, may violate the rights of the child or young boy, who might not have chosen to be circumcised.

On the other hand, there may be little or no justification to perform circumcision on men at an age where little or no protective effect has been demonstrated. In addition, circumcision may create a false sense of security that might lead to increased risk-taking behavior (see below). Another ethical issue relates to the behavioral messages that are provided in the context of circumcision. While circumcision offers some degree of protection, it does not prevent all HIV acquisition. Care should be taken that promotion of male circumcision acknowledges the limitations of the protective effect and the need for safe sexual behavior and

14 condom use. This is particularly important because some circumcised men may consider their circumcision status a reason for not using condoms, thus further reducing women's ability to negotiate safer sex.

\section{Recommendations}

* Explore and test messages about male circumcision vis-à-vis FGC.

* Explore and test informed consent procedures, including questions about who gives consent.

* Explore and test the mix of messages that should be used to promote and communicate the benefits and limitations of male circumcision at different ages.

* Explore and test socialization messages that promote genderequitable concepts of masculinity and sexuality. 
Is Male Circumcision a Feasible Public Health Intervention?

The feasibility of male circumcision is determined by the availability of resources in terms of health infrastructure, trained personnel, and commodities, as well as the costs associated with implementing the intervention. To implement a safe male circumcision program, appropriate standards for training, techniques, and counseling are required, and an adequate package of surgical instruments and other commodities must be available. Resources differ greatly from country to country, and a careful assessment is necessary to determine whether safe male circumcision can be introduced and at what cost. This could be facilitated by the use of a rapid assessment tool.

In terms of cost, both the direct cost and the opportunity costs to the health care system should be considered. The direct costs include the cost of training staff, supplying health facilities with the required equipment and consumables, and supervision and quality control. The opportunity costs include public health programs and activities that are replaced by male circumcision activities. In other words, funding and staff time allocated to male circumcision instead of other prevention activities.

In terms of the infrastructure and direct costs, the following should be considered:

* What are the minimum standards for training, techniques, and counseling that should be in place, and what is the minimum package of surgical instruments, commodities, and medication that should be consistently present in health facilities?

* What resources, such as properly equipped facilities and adequately trained staff, currently exist for performing male circumcisions?

* What is the lowest level of the health care system where male circumcision can be made available?

* Can the health infrastructure cope with a routine male circumcision program? 


\section{Horizons}

\section{Recommendations}

* Develop and field-test a rapid assessment tool for the introduction of male circumcision (such a tool should be adapted from existing rapid assessment tools).

* Develop and field-test a male circumcision training program, including training and resource materials development.

* Test the feasibility of collaboration with the traditional or religious sectors and assess training needs.

* Test the feasibility of different service delivery models, including the use of mobile clinics.

\section{Behavioral Implications of Male Circumcision}

There is anecdotal evidence that, in some population groups, male circumcision is perceived as protective against HIV infection, and it has even been referred to as the "invisible condom." Perceptions of protection may well lead to an increase in risk behaviors, including a reduction in condom use. Men may use their circumcision status as a reason for not using condoms, while women may be less inclined to insist on condom use if their male partners are circumcised.

An increase in risk behavior, including reductions in condom use, will likely continue to put women at risk (possibly an increased risk) and may reduce the potential beneficial effect of male circumcision on HIV transmission. This suggests the need for a cautious approach to introducing male circumcision. Any male circumcision as an intervention to reduce HIV transmission should thus be accompanied by HIV prevention education, counseling, and behavior change interventions, including sustained promotion of condom use.

There are also suggestions that, at least in some cultures, the customs and festivities that surround circumcision ceremonies contribute to considerable sexual risk behavior. ${ }^{22}$
22 Bailey RC, S Neema, and R Othieno. 1999. Sexual Behaviors and Other HIV Risk Factors in Circumcised and Uncircumcised Men in Uganda. J Acquired Immune Defic Syndr 22: 294 301. 


\section{Recommendations}

* Assess perceptions and understanding of male circumcision among both men and women.

* Conduct descriptive behavioral studies in areas where circumcision is currently being done on adolescent and adult males, comparing pre- and post-circumcision sexual risk behaviors to estimate the net behavioral effect of male circumcision.

\section{The Effect of Male Circumcision on Male-to-Female Transmission of HIV}

While there is relational evidence of a protective effect of male circumcision on acquisition of HIV infection by men, the effect of male-to-female transmission has not been studied. There are some indications that HIV-positive circumcised men may be less likely to transmit HIV infection to their female partners, but this needs further study.

\section{Recommendation}

* Study (or analyze existing data for) the effects of male circumcision on maleto-female transmission.

\section{Cost-effectiveness of Male Circumcision in HIV Prevention}

The actual (direct) cost of implementing a male circumcision program can be estimated following a rapid assessment that examines resources and needs. The cost-effectiveness of large-scale male circumcision interventions should be established under different epidemiological and social conditions before circumcision can be recommended for inclusion in the package of HIV intervention strategies. Cost-effectiveness studies should consider the following questions:

* What are the cost implications of a male circumcision public information campaign?

* What will it cost to upgrade facilities so that they meet acceptable standards for performing male circumcision?

* What criteria should a program manager use to rank male circumcision among proven HIV prevention strategies? 


\section{Horizons}

* For the cost of circumcising one male, how many males could be reached with condoms or another intervention?

* What are the medical and social cost implications to parents and young men who opt for circumcision?

* What are other costs, in addition to the procedure itself, of offering a male circumcision intervention (such as voluntary HIV counseling and testing, which could be offered prior to circumcision in the case of older males who may have already contracted HIV)?

* To what degree could the benefit of male circumcision be offset by increased risk behavior and reduced condom use? In order to address how many lives might be saved with either a large-scale or targeted male circumcision intervention (focusing on high-risk, seronegative males), mathematical modeling can be used to estimate both the short- and long-term impact of male circumcision on HIV transmission under different conditions. Existing models could possibly be expanded with variables relating to male circumcision to evaluate the potential effects of the intervention in different settings. Modeling could be based on data available through large community-based studies, such as the trials in Mwanza, Tanzania, and Rakai, Uganda. Very little is known about circumcision practices in southern Africa, and modeling may offer suggestions about populations or countries that would benefit most from male circumcision, as well as the cost-effectiveness of a proposed male circumcision intervention.

Research questions:

* What lessons can we learn from existing male circumcision interventions and what can be replicated elsewhere?

* What type of modeling should be used to assess the feasibility of male circumcision as an HIV intervention?

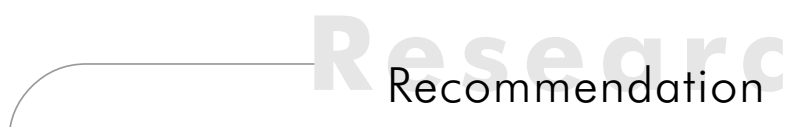

* Model the effect of male circumcision on HIV incidence in different populations at different stages of the epidemic. 


\section{Conclusion and Recommendations}

B ased on the discussions during the two-day meeting, participants determined that there is considerable evidence supporting a protective effect of male circumcision on HIV infection in men in sub-Saharan Africa. Participants also concluded that there are many unknowns. These relate not only to the mechanisms and expected effect of male circumcision on HIV infection and the possible existence of serious confounders, but also on the practicality, feasibility, acceptability, and cost-effectiveness of male circumcision as an HIV intervention. Little is known about the impact and cost-effectiveness of male circumcision among high-risk versus lower-risk seronegative men.

To answer many of the concerns above, randomized controlled trials should ideally be conducted, and the effects of a number of other variables on HIV transmission need to be studied. Such RCTs should probably be conducted among potentially highrisk males, where they may be less time-consuming and more feasible. Not enough is known about the relationship between age at circumcision and risk of HIV infection. The effect of male circumcision on male and female risk behavior and condom use is not known, but behavioral changes related to circumcision status that result in increased risk behavior could reduce the beneficial effect of male circumcision. The operational aspects of introducing a male circumcision program and of maintaining quality and guaranteeing safety should also be explored.

Thus, while it may be premature to recommend male circumcision in currently non-circumcising communities, research on male circumcision should be done in populations where circumcision is currently practiced, and acceptability studies can be done elsewhere. A rapid assessment tool that examines the feasibility and cost of male circumci- 


\section{Horizons}

sion interventions should be developed and operations research conducted in preparation for possible male circumcision programs.

\section{Recommendations for Public Health Research}

* Further explore the biological role of the foreskin and mechanisms of male infection with HIV to better understand the protective effect of circumcision against HIV.

* Conduct randomized controlled trials of a male circumcision intervention that examines its efficacy to prevent HIV infection.

* Conduct studies on the effect of pre-and post-coital hygiene among men and women as it relates to HIV transmission.

* Conduct studies to assess the effect of other variables, including religion, on HIV transmission.

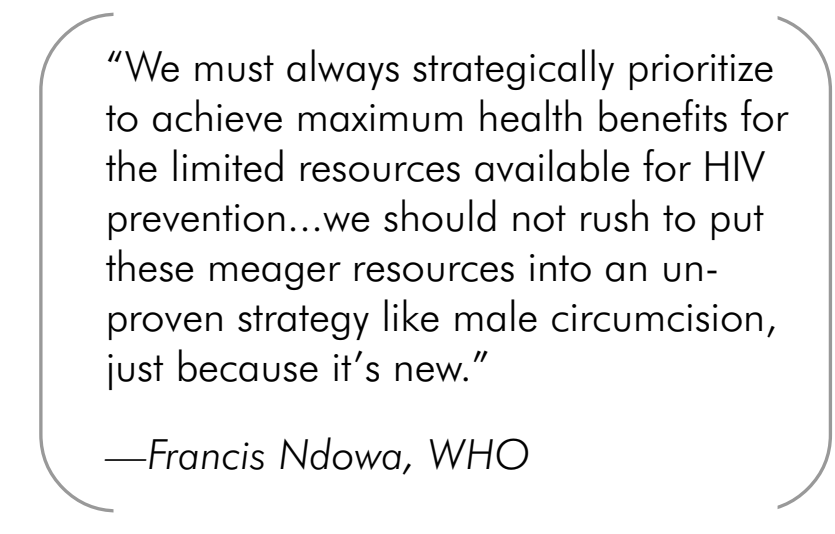

* Conduct longitudinal studies of circumcised men who are not infected with HIV to see if and why some of them become infected with HIV over time.

* Conduct descriptive studies of attitudes and beliefs about male circumcision as an acceptable HIV intervention.

* Assess the utilization of male circumcision services and the quality of care of current male circumcision practices both in clinical and informal settings (i.e., examine where people go, who performs male circumcision, what is communicated and understood about the practice, what the level of training is, what are the complications that occur, how frequent they are, and how the community is being served in terms of its needs). 
* Test mechanisms for implementing voluntary, safe, and effective male circumcision interventions, including the provision of training and supervision for traditional healers and allopathic health care providers.

* Conduct observational studies of traditional male circumcision practices, including an assessment of client and parent understanding.

* Conduct studies to examine the transmissibility of HIV infection by circumcised and uncircumcised men to women.

* Integrate circumcision questions and nest male circumcision studies in ongoing intervention studies. Consider including male circumcision questions in the DHS questionnaire.

* Evaluate the potential cost-effectiveness of male circumcision through mathematical models.

\section{Recommendations for the Horizons Project}

Given its mandate to apply an operations research approach to the identification, analysis, description and dissemination of best practices in HIV prevention and reduction of the impact of the HIV/AIDS epidemic, Horizons should:

* Where possible, integrate assessments of attitudes toward and acceptability of male circumcision in ongoing studies in circumcising and non-circumcising populations.

* Develop and field-test a rapid assessment tool to assess the feasibility and cost of introducing male circumcision.

* Collaborate in modeling the costs and potential impact of male circumcision in different epidemiological situations and in different populations.

* Develop proposals for longer-term studies on cost and safety and outcomes of male circumcision in the context of HIV prevention. 


\section{Horizons}

\section{References}

AIDS epidemic update: December 1999. Geneva: UNAIDS and WHO.

Bailey RC, S Neema, and R Othieno. 1999. Sexual Behaviors and Other HIV Risk Factors in Circumcised and Uncircumcised Men in Uganda. J Acquired Immune Defic Syndr 22: 294-301.

Bailey RC. 1999. UNAIDS Technical Update: Male Circumcision and HIV Prevention. First Draft.

UNAIDS, Geneva.

Bailey RC. 2000. personal communication.

Buve A for the Study Group on Heterogeneity of HIV Epidemics in African Cities. 2000. HIV/AIDS in Africa: Why So Severe, Why So Heterogeneous? Presented at the $7^{\text {th }}$ Conference on Retroviruses and Opportunistic Infections, Abstract S28, San Francisco, CA, USA, Jan $30-$ Feb 2.

Cameron DW, JN Simonsen, LJ D'Costa et al. 1989. Female to male transmission of human immunodeficiency virus type 1: risk factors for seroconversion in men. Lancet 2 (8660): 403-7.

Cohen MS. 2000. Preventing Sexual Transmission of HIV - New Ideas from Sub-Saharan Africa. New Engl J Medicine 342 (13): 970-2.

Gray Ron. 2000. personal communication.

22 Halperin D \& RC Bailey. 1999. Male circumcision and HIV infection: 10 years and counting. Lancet 354 (192): 1813-5.

Hayes R, H Weiss and M Quigley. 1999. Meta-analysis on the relationships between male circumcision and HIV infection. Presented at the $13^{\text {th }}$ meeting of the ISSTDR, Denver, Colorado, USA, 11-14 July.

Kalibala S. 2000. personal communication.

Kelly R, N Kiwanuka, MJ Wawer et al. 1999. Age of male circumcision and risk of prevalent HIV infection in rural Uganda. AIDS 13: 399-405.

Moses S, JE Bradley, NJD Nagelkerke et al. 1990. Geographical Patterns of Male Circumcision Practices in Africa: Association with HIV Seroprevalence. Int J Epidemiology 19 (3): 693-7.

O'Farrell N. 1993. Soap and water prophylaxis for limiting genital ulcer disease and HIV-1 infection in men in sub-Saharan Africa. Genitourin Med 69: 297-300.

Pépin J, M Quigley, J Todd et al. 1992. Association between HIV-2 infection and genital ulcer diseases among male sexually transmitted disease patients in The Gambia. AIDS 6: 89-93.

Soto-Ramirez LE, B Renjifo, MT McLane et al. 1996. HIV-1 Langerhans' cell tropism associated with heterosexual transmission of HIV. Science 71: 1291-3. 


\title{
Appendix A:
}

\author{
List of Participants
}

Bertran Auvert

Professor of Public Health

Institut national de la santé et de la recherche médicale (INSERM)

Hôpital National de Saint-Maurice

14, rue du Val d'Osne

94415 Saint-Maurice Cedex

France

Tel: 3314513871

Fax: 33145183889

Email: Bertran.auvert@paris-ouest.univ-paris5.fr

Robert Bailey

Professor of Epidemiology and Anthropology

Division of Epidemiology and Biostatistics

School of Public Health

University of Illinois at Chicago

2121 W. Taylor Street

Chicago, IL 60612

Tel: (312) 355-0440

Fax: (312) 996-0064

Email: rcbailey@uic.edu

Chris Castle

Program Associate, Horizons Project/

The HIV/AIDS Alliance

4301 Connecticut Avenue, Suite 280

Washington, DC 20008

Tel: 202-237-9412

Fax: 202-237-8410

Email: ccastle@pcdc.org

Sam Clark

Program Coordinator

Program for the Appropriate

Technology in Health (PATH)

1990 M Street, NW

Washington, DC 20036

Tel: 202-822-0033

Fax:202-457-1466

Email: sclark@path-dc.org
Barbara (Brazey) de Zalduondo

Technical Advisor

Center for Population, Health and Nutrition

U.S. Agency for International

Development (USAID)

Washington, DC 20523-3700

Tel: 202-712-1325

Fax: 202-216-3046

Email: bzalduondo@usaid.gov

Andy Fisher

Director, Horizons Project

Population Council

4301 Connecticut Avenue, NW, Suite 280

Washington, DC 20008

Tel: 202-237-9407

Fax: 202-237-8410

Email:afisher@pcdc.org

Tina Gryboski

Program Coordinator

PATH

1990 M Street, NW

Washington, DC 20036

Tel: 202-822-0033/ext.216

Fax: 202-457-1466

Email:kgrybos@path-dc.org

Rod Hoff

Chief of the Prevention Sciences Branch

Vaccine and Prevention Research Program

Division of AIDS

National Institute of Allergy and Infectious

Diseases/ National

Institutes of Health

6700B Rockledge, Rm 4157

Bethesda, MD 20892-7620

Tel: 301-496-6179

Fax:301-402-3684

Email:rh25v@nih.gov 


\section{Horizons}

Sam Kalibala

Program Associate, Horizons Project

General Accident House

Ralphe Bunche Road

P.O. Box 17643

Nairobi, Kenya

Tel: 254-2-713-4801/2/3

Fax: 254-2-713-479

Email:skalibala@popcouncil.or.ke

Purnima Mane

Director, Program Planning

Population Council

Washington DC \& New York offices

Tel: 202-237-9403/ 212-339-0500

Fax: 202-237-8410/212-755-6052

Email:pmane@pcdc.org

pmane@popcouncil.org

Elaine Murphy

Director, Women's Reproductive Health

Initiative

PATH

1990 M Street, NW

Washington, DC 20036

Tel: 202-822-0033

Fax: 202-457-1466

Email: emurphy@path-dc.org

Francis J. Ndowa

Medical Officer

HIV/AIDS and Sexually Transmitted Infections

World Health Organization (WHO)

20 Avenue Appia

$\mathrm{CH}-1211$ Geneva 27 Switzerland

Tel: 00-41-22-791-2111

Fax: 00-41-22-791-3111

Email:ndowaf@who.ch

Kerry Richter

Deputy Director of Research

AIDSMark/Population Services International

1120 19th Street, NW Suite 600

Washington, DC 20036

Tel: 202-785-0072

Fax: 202-785-0120

Email:krichter@psiwash.org
Zeda Rosenberg

Scientific Director

HIV Prevention Trials Network

Family Health International

2101 Wilson Blvd., Suite 700

Arlington, VA 22201

Tel: 703-516-9779

Fax: 703-516-9781

Email: zrosenberg@fhi.org

Thomas M. Rehle

Associate Director

HIV/AIDS Prevention and Care Department

Family Health International

2101 Wilson Blvd, Suite 700

Arlington, VA 22201

Tel: 703-516-9779

Fax:703-516-9781

Email:trehle@fhi.org

Naomi Rutenberg

Research Director, Horizons Project

Population Council

4301 Connecticut Avenue, NW, Suite 280

Washington, DC 20008

Tel: 202-237-9405

Fax: 202-237-8410

Email: nrutenberg@pcdc.org

Caroline Ryan

Associate Director

International Activities

Division of STD Prevention

National Center for HIV, STD and

TB Prevention

Centers for Disease Control and Prevention

DSTDP, E-02

1600 Clifton Road

Atlanta, GA 30333

Tel: 404-639-8272/404-639-8275

Fax: 404-639-8609

Email:cgr8@cdc.gov 
David Stanton

Technical Advisor

Center for Population, Health and Nutrition

U.S. Agency for International

Development (USAID)

Washington, DC 20523-3700

Tel: 202-712-5681

Fax: 202-216-3046

Email:dstanton@usaid.gov

Johannes van Dam

Deputy Director, Horizons Project

Population Council

4301 Connecticut Avenue, NW, Suite 280

Washington, DC 20008

Tel: 202-237-9406

Fax: 202-237-8410

Email: jvandam@pcdc.org

Ellen Weiss

Program Associate

Horizons Project - International Center for

Research on Women

4301 Connecticut Avenue, NW, Suite 280

Washington, DC 20008

Tel: 202-237-9402

Fax: 202-237-8410

Email: eweiss@pcdc.org

Helen Weiss

Lecturer in Medical Statistics

Infectious Diseases Epidemiology Unit

Department of Infectious and

Tropical Diseases

London School of Hygiene and Tropical

Medicine, Room 105 a

Keppel Street

London WCIE 7HT UK

Tel: 01716127872

Fax: 01714364230

Email: Helen.weiss@lshtm.ac.uk 


\section{Horizons}

Appendix B:

Meeting Agenda

Monday, February 7, 2000

9:00-9:05 Opening remarks David Stanton, USAID

9:05-9:15 Introduction and objectives Johannes van Dam, Horizons

$9: 15-9: 35$

Meta-analysis of circumcision and HIV

Helen Weiss, LSHTM, London, UK

9:35 - 9:55 Overview of the literature

Robert Bailey,

University of

Illinois at Chicago

9:55 - 10:05 Urban African Multi-site study

Bertran Auvert, University of Paris

10:05-10:45 Discussion of the current research

10:45-11:05 Coffee

11:05-11:20 Social and behavioral perspective

$11: 20-11: 35 \quad$ Gender perspective

Sam Kalibala, Horizons

Ellen Weiss, ICRW/Horizons

11:35 - 12:30 Discussion on ethical, community, religious, gender, and child rights issues

$12: 30-13: 15 \quad$ Lunch 


\begin{tabular}{|c|c|c|}
\hline $13: 15-13: 25$ & Experiences in Kenya & Robert Bailey \\
\hline $13: 25-13: 40$ & $\begin{array}{l}\text { UNAIDS and WHO views: programmatic } \\
\text { perspectives }\end{array}$ & Francis Ndowa, WHO \\
\hline $13: 40-14: 30$ & Discussion on programmatic issues & \\
\hline $14: 30-15: 00$ & Coffee/tea & \\
\hline $15: 00-16: 30$ & $\begin{array}{l}\text { Identification of research issues, with a focus } \\
\text { on practical programmatic research questions } \\
\text { and testable program interventions }\end{array}$ & \\
\hline $16: 30-16: 45$ & Wrap-up and conclusions & Johannes van Dam \\
\hline $6: 45-17: 00$ & Closing & $\begin{array}{l}\text { Andy Fisher, } \\
\text { Horizons }\end{array}$ \\
\hline
\end{tabular}

Tuesday, February 8, 2000

Venue: Horizons office, 4301 Connecticut Ave NW, Suite 280, Washington

9:00 - 12:30 Discussion in smaller group: Formulation of research questions that can be addressed within Horizons' mandate; discussion of appropriate research methodologies; identification of sites, partners

$12: 30$

Lunch 